\title{
Wind differentiates reproduction in the non-expansive Black Tern Chlidonias niger and the expansive White-winged Tern Chlidonias leucopterus
}

\author{
Artur Golawski $\cdot$ Zbigniew Kasprzykowski $\cdot$ Emilia Mroz
}

Received: 20 July 2016/Accepted: 26 December 2016/Published online: 30 December 2016

(C) The Author(s) 2016. This article is published with open access at Springerlink.com

\begin{abstract}
Identifying the key factors governing the expansion of a species' range is difficult because of the multiple interactions of environmental and biological factors. Among the biological factors are breeding parameters, which at the edge of a species' range may indicate the traits involved in limiting species distribution. To evaluate whether the hatching success of two sympatric species of terns was dependent on weather parameters, a study was carried out in the valley of the River Bug in eastern Poland. During 2007-2010, nine colonies with 113 clutches of Whitewinged Tern (CHL, an expansive species, new to the region since 1997) and 92 clutches of Black Tern (CHN, a non-expansive species, nesting in stable numbers in this region for many years) were monitored. CHN arrived on average 9 days earlier than CHL. While CHN arrived in east-central Poland earlier and earlier during the 1998-2013 period, no such trend was recorded for CHL. The clutch initiation median in
\end{abstract}

Handling editor: Piet Spaak.

A. Golawski $(\bowtie) \cdot$ E. Mroz

Department of Zoology, Faculty of Natural Science,

Siedlce University of Natural Sciences and Humanities,

Prusa 12, 08-110 Siedlce, Poland

e-mail: artur.golawski@uph.edu.pl

Z. Kasprzykowski

Department of Ecology and Nature Protection, Faculty of Natural Science, Siedlce University of Natural Sciences

and Humanities, Prusa 12,08-110 Siedlce, Poland
CHL was 8 days later than in $\mathrm{CHN}$. The hatching success of CHL was statistically less than that of CHN (41.6 vs. $69.6 \%$ ). A general discriminant analysis model showed that successful CHL clutches depended on the maximum daytime wind speed (strong winds can be disastrous for breeding terns), colony identity and clutch initiation date. In the case of CHN, none of these factors had a statistically significant influence on hatching success, although the clutch initiation date was very close to being significant. These results suggest that a species which nested in the same location for a long time in relation to ambient weather conditions has higher hatching success than the one which is in the process of expanding its distribution range.

Keywords Abiotic factors - Adaptations - Breeding parameters $\cdot$ Expanding population $\cdot$ Peripheral population

\section{Introduction}

The dispersal of organisms is a natural process limited by multiple barriers (Newton 1998; Møller et al. 2004; Massa et al. 2014). The degree to which species adapt to novel environments is important to a range of topics in ecology and evolution (Wiens et al. 2010). Despite considerable interest in the subject, our understanding of the power of environmental factors to constrain 
geographic ranges remains relatively poor (Gaston 2009; Pigot et al. 2010; Strubbe and Matthysen 2014). The identification of key factors affecting the expansion process is difficult, since this is usually caused by multiple interacting factors like the availability of new food resources (Duhem et al. 2008), suitable breeding habitats (Veech et al. 2011; Ledwoń et al. 2014) or adverse changes in breeding habitats forcing the breeding population to leave (Oro and Ruxton 2001).

At the edge of an animal's distribution range, abiotic factors are also extremely important: climate often represents a first step in the limitation of a species' range (Root 1988). Therefore, weather should have a greater influence on demographic rates in peripheral areas than in central areas (Boyd 1987). Species living in wet habitats disperse farther than those living in dry habitats, a phenomenon that can be explained by the greater patchiness of wet habitats in space and time (Paradis et al. 1998). To achieve breeding success, birds must breed only when conditions, including weather, are suitable for the production of chicks (Wallen and Schneider 1999).

The White-winged Tern Chlidonias leucopterus (CHL) and Black Tern Chlidonias niger (CHN) are two sympatric species inhabiting river valleys in eastcentral Poland. The westernmost regular breeding site of CHL in Europe, this area has been a permanent CHN breeding site for many years (Cramp 1985; Tomiałojć and Stawarczyk 2003). The typical nesting habitat of CHL is assumed to be naturally waterlogged grassland (Kapocsy 1979; Cramp 1985), but in dry seasons in east-central Poland this species has occurred on ox-bow lakes (Dombrowski et al. 2014). During the high water period, CHL in east-central Poland (study area) located their colonies in waterlogged sedge fields three times more often than CHN did, while the latter nested three times more frequently on ox-bow lakes (Golawski et al. 2015). The range of CHL in Europe originally covered the eastern part of the continent, with isolated sites in NE Poland, Hungary and Romania (Cramp 1985). In the last 20 years, however, a westward expansion of this tern has been taking place in Europe, and CHL nests farther west in Poland, and even in Germany, Denmark and the Netherlands (Grell and Rasmussen 1997; Głowaciński 2001; Boele and Ebels 2007; Gruneberg and Boschert 2009; Ławicki et al. 2011). The number of pairs has risen conspicuously in east-central Poland, where the species has been breeding regularly since 1997. At that time, a mere 30 pairs were reported from there, but now the number of pairs can exceed 1000 in some years (Golawski et al. 2016a). From time to time, numbers during spring migration in eastern Poland reach thousands of individuals. In turn, $\mathrm{CHN}$ numbers have been more stable over the last 30 years, with a breeding population of between 480 and 650 pairs in east-central Poland (Dombrowski et al. 2014).

CHL and CHN are roughly the same size, with a body weight of ca $70 \mathrm{~g}$. Both species usually lay three eggs, the dimensions of which are very similar $(35 \times 25 \mathrm{~mm})$, and both build nests of much the same size, i.e. with a diameter of $\mathrm{ca} 15 \mathrm{~cm}$, and they need a strong base for the nest site. The eggs are incubated for some 20 days and the hatchlings fledge after ca 24 days (Cramp 1985).

In this paper, we attempt to compare arrival date of two tern species and to evaluate whether the hatching success differs with respect to weather parameters. Knowledge of breeding parameters at the edge of a species' range may indicate the traits involved in limiting species distribution (Lawton 1996; García and Arroyo 2001). It was anticipated that both tern species would achieve similar breeding parameters because they nest in similar weather conditions and the same type of vegetation, mainly Water Soldier Stratiotes aloides.

\section{Materials and methods}

\section{Study area}

The study area lies in the valley of the River Bug near the village of Morzyczyn in east-central Poland $\left(52^{\circ} 40^{\prime} \mathrm{N}, 21^{\circ} 54^{\prime} \mathrm{E}\right)$. This area is the westernmost regular breeding site of CHL in Europe and has long been known as a permanent breeding site of $\mathrm{CHN}$ (Fig. 1; Tomiałojć and Stawarczyk 2003). The Bug is one of the largest rivers in Poland protected within the Natura 2000 network, with abundant breeding sites like ox-bow lakes (Golawski et al. 2015). All the oxbow lakes investigated supported a similar vegetation-mostly Water Soldier, White and Yellow Water Lilies Nymphaea alba and Nuphar lutea and Frogbit Hydrocharis morsus-ranae. The ox-bow lakes were 27-33 ha in area and 1.4-1.7 $\mathrm{m}$ in depth. 
Fig. 1 Range of Black Tern Chlidonias niger and Whitewinged Tern Chlidonias leucopterus in Europe. Data according to: Gochfeld and Burger (2016), Gochfeld et al. (2016)

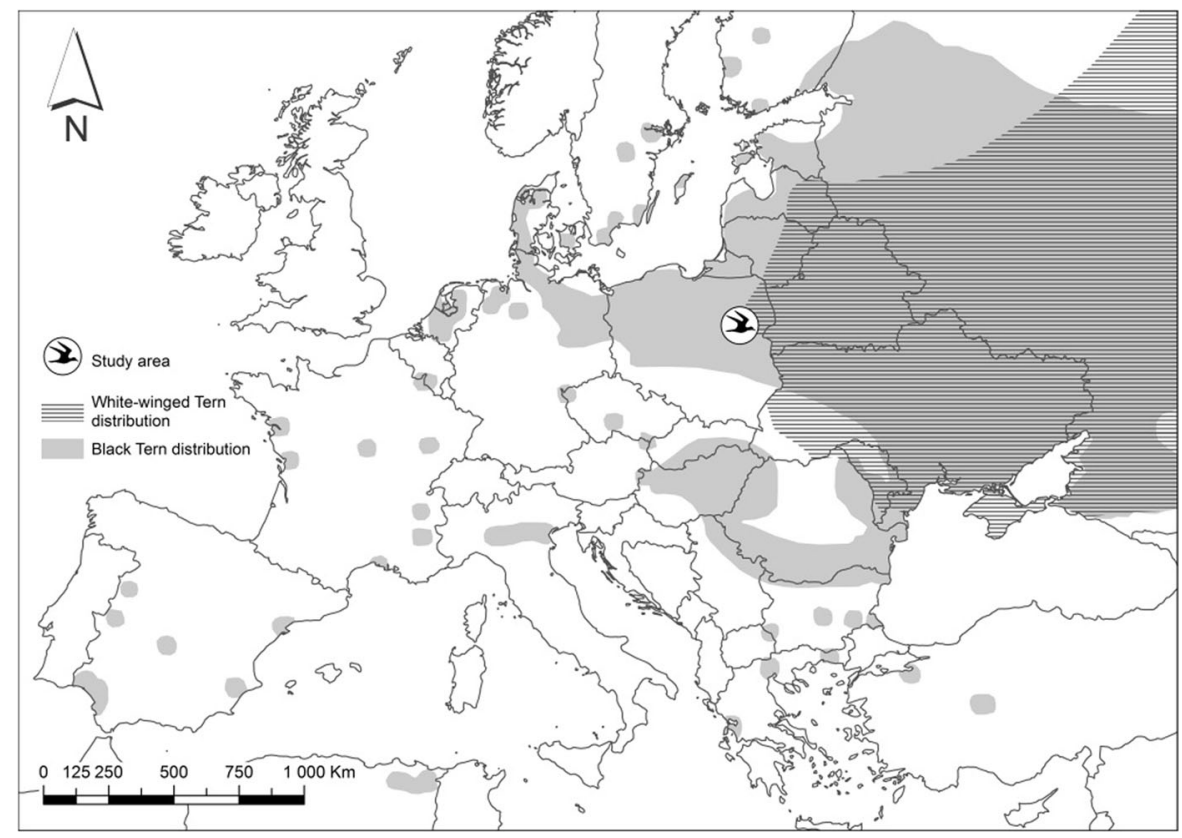

Bird arrival data

The arrival dates of these terns for the period 1998-2013 were taken from the database set up by members of the Mazowsze-Świętokrzyskie Society for the Protection of Birds, who monitored these birds in east-central Poland, including our study area. The number of observers in each year was similar, and observations were carried out every 2-3 days. This paper uses data on the first appearance of an individual in a given year.

\section{Reproductive data}

The fieldwork for this study was carried out in the four seasons from 2007 to 2010. During this time, nine colonies of $\mathrm{CHN}$ and CHL were monitored. Both species either breed in mixed colonies or separately; in the latter case no more than $20 \mathrm{~m}$ from each other, as the nests were situated in the same patch of Water Soldier. During this study, 113 CHL clutches and 92 $\mathrm{CHN}$ clutches were described. Nest inspections began around 15-20 May, that is, when the first eggs were laid (clutch initiation) and continued until early July, when the last hatchlings appeared. As a rule, nests were visited once a week, but in the period when hatching was anticipated, they were inspected every 3-4 days. The nest inspection dates were chosen so as to include the hatching peak: this was worked out from the estimated laying date and the average incubation period of 20 days, assuming that eggs were laid at 1-day intervals (Cramp 1985). The great majority of nests were found during the egg-laying period or at the start of incubation, so we were able to determine the hatching date of nestlings with an accuracy of \pm 1 day. Likewise, we were able to work out the clutch initiation data with a similar accuracy. In determining the hatching date, we also used body mass measurements of nestlings in or right beside the nest and compared these figures with those of nestlings of known hatching date. Every year the first inspection involved searching for nests in all or part of the breeding colony. To this end, an inflatable dinghy was used to gain access to the nests on the ox-bow lakes. The positions of the nests were mapped, and a marker was placed in the field near each one. The fates of all the tern nests were monitored as they appeared throughout the breeding season.

A clutch was regarded as lost if the nest was destroyed by water or had been abandoned before the estimated hatching date (Mazzocchi et al. 1997). A clutch was considered to have been abandoned if the eggs were cold during consecutive inspections. Clutches destroyed by water included those that had been inundated or had sunk completely into the water together with the patch of Water Soldier on which the 
nest had been built. Clutches depredated by predators, probably by corvids Corvidae, were not included in this analysis (empty nest before the estimated date of hatching, lack of adults). We also rejected three nests, whose fate we were not sure of. A successful brood was defined as having produced at least one hatchling, which was observed on or near the nest (the chicks remain close to the nest for a few days after hatching).

\section{Weather data}

We analysed three groups of explanatory variables (weather conditions) that could have affected the hatching success of terns (Table 1). We analysed the weather parameters for the 7 days before the loss of unsuccessful nests and the 7 days before the hatching of clutches in successful nests; these analyses therefore cover all clutches. We took this period into consideration because the time elapsing between two successive inspections of the tern colonies was $6.6 \pm 2.4$ days. The weather conditions, including the air temperature on a given day, are especially important for proper embryonic development (Conway and Martin 2000; Olson et al. 2006). This is particularly the case with terns, which often interrupt their incubation of eggs in order to feed or to defend their clutches against predators. The first group of weather conditions described temperature $\left({ }^{\circ} \mathrm{C}\right)$ : the mean ambient temperature, as well as the maximum and minimum daytime temperature during these 7 days. The second group of explanatory variables reflected precipitation $(\mathrm{mm})$, i.e. total precipitation and maximum daytime precipitation. The third group of variables included wind speed $(\mathrm{km} / \mathrm{h})$ : the mean wind speed during the 7 days and the maximum daytime wind speed. The variables were log-transformed. Weather data were obtained from the website http://www.tutiempo.net for the nearest weather station in the town of Ostrołęa.

\section{Statistics}

To assess whether hatching success was affected by weather conditions, we compared the fate of nests (dependent variable, hatched vs. not hatched) with the above-mentioned independent variables using general discriminant analysis (GDA, Hill and Lewicki 2007) in the module provided by Statistica 10.0 (StatSoft 2012). In order to avoid multi-collinearity of regressors, parameters (weather conditions) with the strongest correlation between them $(\geq 0.7)$ were eliminated manually. Colony identity (ID) and clutch initiation date (expressed as $1=7$ May) as predictors were added in the analysis. Numbers from 1 to 9 were assigned to colonies according to the order of control's time.

Table 1 Comparison of weather conditions (mean \pm SD) between clutches with hatching success and without hatching success of two species of terns breeding in east-central Poland

\begin{tabular}{|c|c|c|c|c|c|c|}
\hline \multirow[t]{2}{*}{ Variables } & \multicolumn{3}{|c|}{ White-winged tern } & \multicolumn{3}{|l|}{ Black tern } \\
\hline & $\begin{array}{l}\text { With success } \\
n=47\end{array}$ & $\begin{array}{l}\text { Without success } \\
n=66\end{array}$ & AUC & $\begin{array}{l}\text { With success } \\
n=64\end{array}$ & $\begin{array}{l}\text { Without success } \\
n=28\end{array}$ & AUC \\
\hline Mean temperature $\left({ }^{\circ} \mathrm{C}\right)$ & $19.7 \pm 2.8$ & $17.0 \pm 3.1$ & 0.263 & $17.6 \pm 2.9$ & $16.7 \pm 3.4$ & 0.376 \\
\hline $\begin{array}{l}\text { Maximum daytime temperature } \\
\left({ }^{\circ} \mathrm{C}\right)\end{array}$ & $29.2 \pm 2.9$ & $27.1 \pm 3.2$ & 0.317 & $27.9 \pm 2.3$ & $26.5 \pm 2.8$ & 0.362 \\
\hline $\begin{array}{l}\text { Minimum daytime temperature } \\
\quad\left({ }^{\circ} \mathrm{C}\right)\end{array}$ & $8.0 \pm 2.2$ & $7.8 \pm 3.5$ & 0.511 & $6.6 \pm 3.2$ & $6.7 \pm 3.5$ & 0.518 \\
\hline Total precipitation (mm) & $10.6 \pm 7.2$ & $19.6 \pm 12.1$ & 0.734 & $11.1 \pm 11.1$ & $12.2 \pm 11.3$ & 0.537 \\
\hline $\begin{array}{l}\text { Maximum daytime } \\
\text { precipitation }(\mathrm{mm})\end{array}$ & $6.1 \pm 4.6$ & $11.3 \pm 9.7$ & 0.698 & $5.3 \pm 4.8$ & $5.5 \pm 5.9$ & 0.497 \\
\hline Mean wind $(\mathrm{km} / \mathrm{h})$ & $7.2 \pm 1.2$ & $8.7 \pm 1.8$ & 0.693 & $7.5 \pm 1.6$ & $8.3 \pm 1.3$ & 0.582 \\
\hline $\begin{array}{l}\text { Maximum daytime wind }(\mathrm{km} / \\
\mathrm{h})\end{array}$ & $18.3 \pm 2.6$ & $21.4 \pm 3.5$ & 0.701 & $17.9 \pm 2.5$ & $19.0 \pm 3.2$ & 0.615 \\
\hline
\end{tabular}

$A U C$ Area under the ROC (receiver-operating characteristic) curve 
Accordingly, two parameters describing temperature, i.e. one describing precipitation and one describing wind speed, were eliminated. In consequence, we used only three variables to describe weather conditions. These were minimum daytime temperature, total precipitation and maximum daytime wind speed.

To assess the goodness of fit of each weather parameter on the hatching success of the terns, we used the area under the receiver-operating characteristic (ROC) curve and the area under the curve (AUC), which ranges from 0 to 1 and measures the variable's ability to discriminate between success and failure events. A value of 1.0 would represent a perfect model, whereas a value of 0.5 would indicate no significant difference between the two states (Fielding and Bell 1997). AUCs were the biggest for minimum daytime temperature, total precipitation and maximum daytime wind speed (Table 1), so we used these parameters in the GDA analysis. This statistical analysis was performed using PQStat 1.6.0 software.

The difference between the hatching successes of the two tern species was assessed with the Chi-squared test. $T$ test was used to assessed the difference between two species in: the clutch initiation date, 7 weather parameters collected 7 days prior to hatching of all clutches (successful and failed) and the arrival dates of the first individual in successive years (expressed as $1=28$ March). Since the distributions of the variables did not deviate from the normal, no transformation of data was necessary. The arrival trend for the 16-year period was assessed with the Spearman correlation. The values are reported as mean $\pm 1 \mathrm{SD}$. Only results with a probability of $\alpha \leq 0.05$ were assumed statistically significant.

\section{Results}

Arrival of terns at their breeding grounds

CHN arrived in east-central Poland between 28 March (2009, extremely early arrival, next early date $=6$ April) and 30 April (2004) (median arrival date-17 April). In contrast, the earliest arrival of CHL was on 18 April (2012) and the latest one on 5 May (2003) (median-26 April). On average, therefore, the arrival dates differed by 9 days, a statistically significant figure ( $t$ test for dependent samples, $t=4.37$, $P<0.001, n=16$ years).
Over the 16 years, $\mathrm{CHN}$ arrived earlier and earlier (Spearman correlation, $r=-0.62, \quad p=0.009$, $n=16$, Fig. 2), whereas the arrivals of CHL in this part of Poland did not display any statistically significant trend (Spearman correlation, $r=-0.32$, $p=0.224, n=16$, Fig. 2).

The effect of weather conditions and clutch initiation date on hatching success

The values of all seven weather parameters analysed were higher for the breeding period of CHL in comparison with CHN (Fig. 3), but significant differences were recorded for only four predictors: total precipitation, maximum daytime precipitation, minimum daytime temperature and maximum wind speed ( $t$ test, $d f=203, p<0.006$ in all cases).

The hatching success of CHL was $41.6 \%(n=113$ clutches), that of CHN was $69.6 \%$ ( $n=92$ clutches); this parameter was statistically significantly different between the species (Yates corrected Chisquared $=14.88, d f=1, \quad p<0.001)$. The GDA model for CHL $\left(F_{5,107}=10.62, p<0.001\right.$, Wilks' Lambda $=0.668)$ included three statistically significant factors influencing the hatching success of this species (Table 2). Successful clutches depended on only one weather factor-the maximum daytime wind speed, the difference between successful and unsuccessful clutches being a wind speed of $3.1 \mathrm{~km} / \mathrm{h}$ (Table 1). Moreover, hatching success was significantly dependent on colony identity and clutch initiation date. Clutches begun earlier achieved better success (Table 2; Fig. 4). The average first egg-laying date was 27 May in successful nests and 30 May in clutches suffering a loss (median for all clutches-28 May). The GDA model for $\mathrm{CHN}\left(F_{5,86}=2.01\right.$, $p=0.085$, Wilks' Lambda $=0.895$ ) did not include any statistically significant factors influencing hatching success. However, one parameter-the clutch initiation date, was very close to being statistically significant (Table 3). As in the previous species, the earlier initiated $\mathrm{CHN}$ clutches achieved better success (Table 3; Fig. 4). The average first egg-laying date was 18 May in successful nests and 24 May in unsuccessful nests (median for all clutches-20 May). The median clutch initiation dates differed significantly between the two tern species $\left(t\right.$ test, $t_{203}=9.93$, $p<0.001)$. 
Fig. 2 Arrival dates in eastcentral Poland of Black Tern Chlidonias niger (black points, solid line) and White-winged Tern Chlidonias leucopterus (white points, dotted line) in 1998-2013

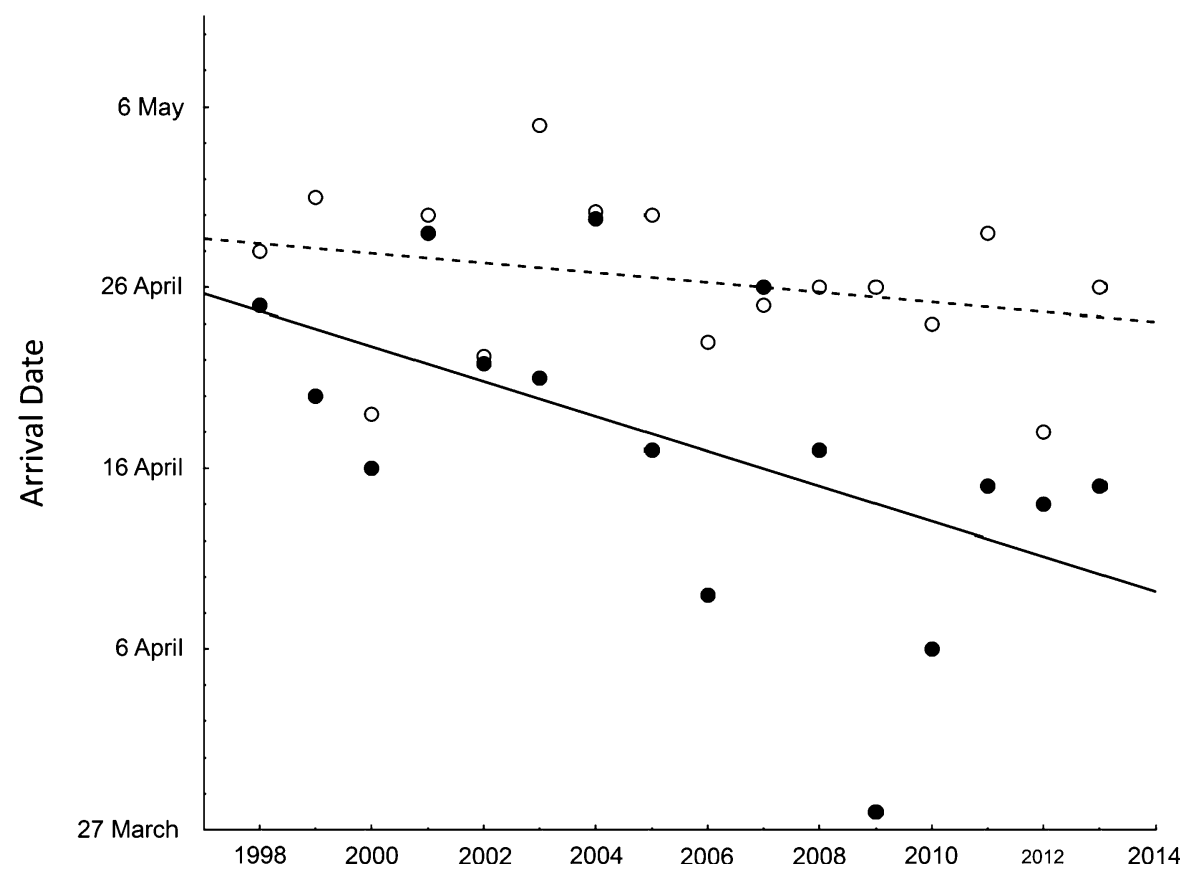

\section{Discussion}

Hatching success was far greater in CHN than in CHL; both species nested in the same patches of vegetation, consisting mostly of Water Soldier. The relation between hatching success and clutch initiation date in $\mathrm{CHN}$ was close to being significant, whereas in CHL this date was statistically highly significant. The earlier the terns started breeding, the better the hatching success in both species. CHL started nesting 8 days later than $\mathrm{CHN}$, probably a consequence of the former's later arrival at the breeding grounds. The factor contributing to the later onset of breeding in CHL may well be the state of the vegetation, which must be better developed in comparison with the requirements of CHN. The preferred habitat of CHL consists of patches of waterlogged sedges, where the terns build their nests on top of sedge clumps, which form solid base for the nests (Cramp 1985). Water soldier, on the other hand, which grows on the ox-bow lakes, has a delicate, less stable structure, especially at the beginning of the growing season. In time, the water soldier patches become denser and more resistant to sinking under the weight of the birds. In the case of the third member of the genus-Whiskered Tern Chlidonias hybrida-a strong association was demonstrated between vegetation growth stage and clutch initiation date (Paillisson et al. 2006). In the case of CHL, the statistical significance of the variable describing colony location (colony identity) indicates that these factors affect the colony as a whole. Within a given colony, there are probably safer spots, which are less exposed to the destructive action of winds, e.g. closer to the shores of ox-bow lakes, but even so, our results show quite clearly that the location of a colony is crucial to the fate of clutches/broods. Extremes of weather, like storms, high winds, floods and abnormally high or low temperatures can destroy entire or significant parts of colonies, resulting in low reproduction for that year (Burger 1982; Frederiksen et al. 2008).

Our analysis showed that only one weather parameter affected hatching success in CHL, namely the maximum daytime wind speed. The average wind speed for failed clutches was higher than for successful ones. In contrast, because storms were not often early in the season they had no effect on the success or failure of a clutch in $\mathrm{CHN}$. The deleterious effect of strong winds was manifested in the movement of quite large patches of water soldier around the ox-bow lake; in extreme cases, individually marked tern nests were shifted up to $350 \mathrm{~m}$ away from their original position. Nests carried such a long distance away were abandoned by the parent birds. In addition, some clutches 
Fig. 3 Comparison of weather conditions (mean $\pm \mathrm{SD}$ ) in the breeding periods of Black Tern Chlidonias niger and White-winged Tern Chlidonias leucopterus in east-central Poland. The statistical differences between the two species of terns were: total precipitation, maximum daytime precipitation, minimum daytime temperature and maximum wind speed ( $t$ test, $d f=203$, $p<0.006$ in all cases)
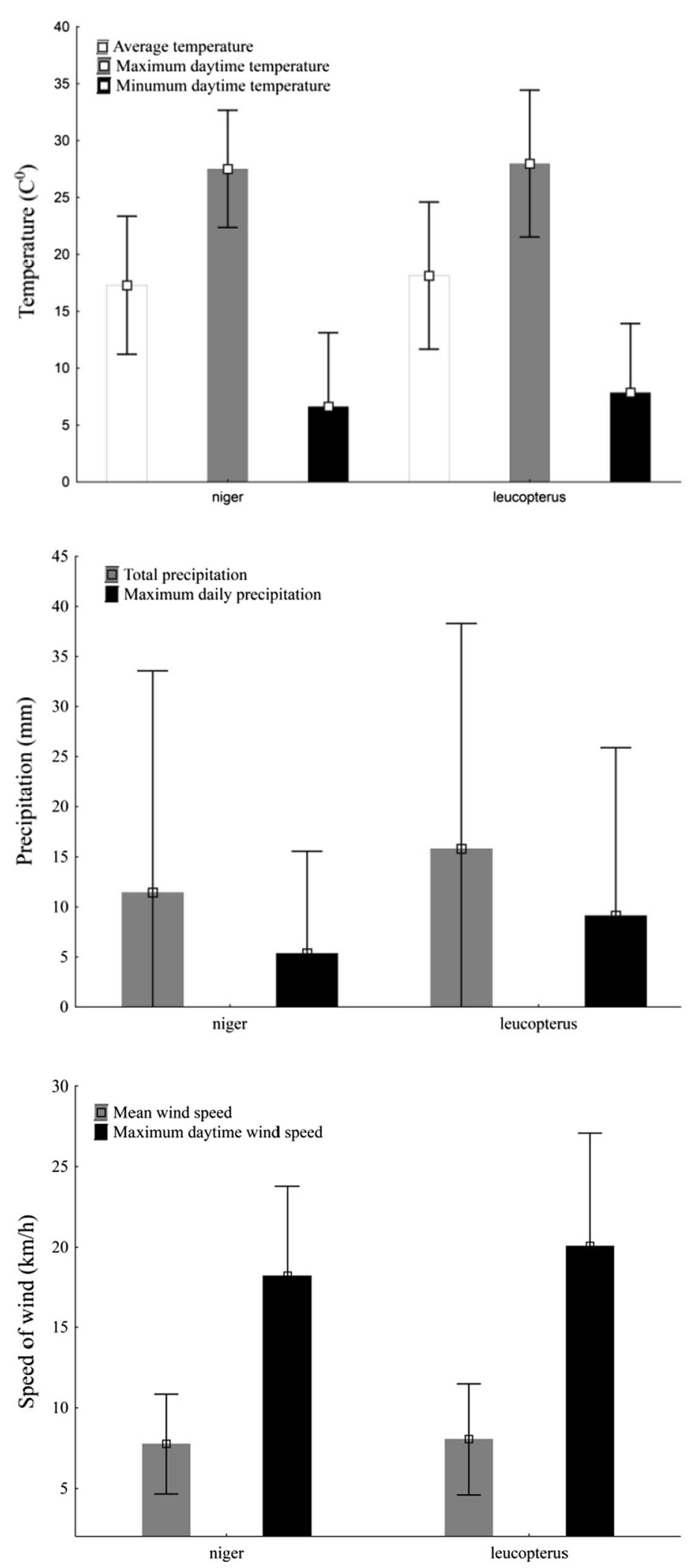
Table 2 Predictor variables obtained from discriminant analyses between nests with hatching success $(n=47)$ and nests without hatching success $(n=66)$ of White-winged Tern Chlidonias leucopterus nesting in east-central Poland

\begin{tabular}{lccrr}
\hline Variable & Coefficient & SE & $F$ & $p$ \\
\hline Minimum daytime temperature & 0.053 & 0.105 & 0.26 & 0.613 \\
Total precipitation & -0.113 & 0.083 & 1.81 & 0.182 \\
Maximum daytime wind & 0.977 & 0.282 & 11.96 & $<0.001$ \\
Colony identity & 0.081 & 0.023 & 12.61 & $<0.001$ \\
Date of clutch initiation & 0.033 & 0.009 & 13.97 & $<0.001$ \\
\hline
\end{tabular}

Fig. 4 Clutch initiation date of Black Tern Chlidonias niger (whiteblack columns) and Whitewinged Tern Chlidonias leucopterus (white-grey columns); dark part of columns-clutches with hatching success, white part of columns-failed clutches

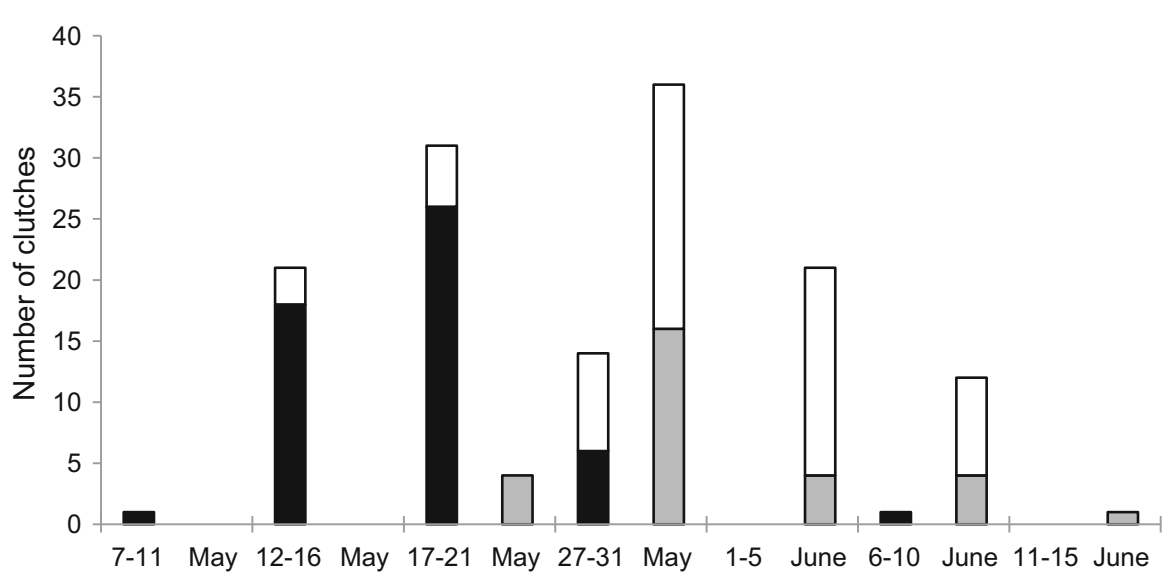

Table 3 Predictor variables obtained from discriminant analyses between nests with hatching success $(n=64)$ and nests without hatching success $(n=28)$ of Black Tern Chlidonias niger nesting in east-central Poland

\begin{tabular}{|c|c|c|c|c|}
\hline Variable & Coefficient & SE & $F$ & $p$ \\
\hline Minimum daytime temperature & -0.071 & 0.089 & 0.63 & 0.429 \\
\hline Total precipitation & -0.008 & 0.092 & 0.01 & 0.928 \\
\hline Maximum daytime wind & 0.416 & 0.352 & 1.40 & 0.241 \\
\hline Colony identity & -0.001 & 0.036 & 0.01 & 0.974 \\
\hline Date of clutch initiation & 0.019 & 0.010 & 3.80 & 0.054 \\
\hline
\end{tabular}

will have perished when patches of water soldier sank; in the clear waters of the ox-bow lake, considerable amounts of water soldier were visible on the bottom, although the eggs could not be found despite intensive searching. Those clutches were probably lost during thunderstorms with their characteristically strong gusts of wind. If the wind blew towards the open waters of the ox-bow lake, fragments of water soldier were torn away from the main patch and blown around over the water. Such events are thus disastrous for breeding terns. The number of strong wind events in
Poland is by far the highest in July (about 340); this is three times more than in June (ca 120) and five times more than in May (ca 70) (Popławska and Grabowska 2013). Between 2000 and 2012, they occurred most often in central Poland (Popławska and Grabowska 2013). The increasing intensity of strong winds in late spring and early summer may therefore be responsible for the differences in breeding success in CHN and CHL, since these two species initiate breeding at different times. Wind has rarely been shown to cause brood losses in Chlidonias terns; in combination with 
rising water levels, e.g. in North America, it has given rise to population losses of up to $15 \%$ (Chapman Mosher 1987). This weather factor is also responsible for the greater mortality and lower growth rate of nestlings in the Eurasian Bittern (Polak and Kasprzykowski 2013; Kasprzykowski et al. 2014). On the other hand, the adverse effect of wind on the fish foraging efficiency of Sterna terns and the consequent poor breeding success or retarded chick development is well known (Ramos et al. 2002).

Although the present analysis did not demonstrate the statistical significance of rainfall on hatching success in CHL, twice as much rain fell when clutches failed than when they were successful. In the case of CHN, rainfall levels were roughly the same for both successful and failed clutches. The higher temperatures obtaining during the CHL breeding period were due to the phenologically later onset of breeding in this species (late spring-early summer) than in CHN. This, in turn, is a consequence of the later arrival of CHL at its breeding grounds in east-central Poland.

This study has shown that wind speed may be a critical factor that can lead to low breeding success in birds in temperate latitudes, and not just in low latitudes (James and Wunderle 1993) or on sea coasts (e.g. van de Pol et al. 2010; Bonter et al. 2014). Another important result is that CHL, which begins breeding on average 8 days later than $\mathrm{CHN}$, had a much lower hatching success. In east-central Poland, a few days of worse weather (greater wind speeds, probably during thunderstorms, the number of which rises between spring and summer) will suffice to cause considerable brood losses on ox-bow lakes. This can be compared with the observation made in many bird populations that brood success decreases as the breeding season progresses (Verhulst and Nilsson 2008), except that in the present case we are dealing with two related species breeding in the same habitat. Such weather-dependent drops in brood success have been described for other tern species, e.g. Roseate Tern Sterna dougallii (Burger et al. 1996) and Common Tern (Arnold et al. 2004; Nisbet et al. 2010). Since breeding onset in CHN and CHL is strictly related to the arrival dates of these species at their breeding grounds, one can attempt to predict their breeding success. CHN is arriving ever earlier; CHL, on the other hand, seems to have been turning up in northern Poland somewhat earlier than usual in recent years (Polakowski 2011), but this apparent trend has not been confirmed statistically. The number of strong wind events in this part of Poland has been increasing in recent years (Popławska and Grabowska 2013), so the breeding success of CHL is likely to deteriorate further. Only in years when flood water levels are high does this species nest in habitats other than ox-bow lakes, i.e. in shallowly inundated sedge beds, where the wind's strength is not of such significance as on the ox-bow lakes. In this area, the hatching success of eggs was significantly higher and the number of hatchlings per pair of CHL was also higher in waterlogged sedges than in ox-bow lakes (Golawski et al. 2016b). On the other hand, up to $31 \%$ of clutch losses on the waterlogged sedges were due to predation, and only $2 \%$ of nests sank into the water (Golawski et al. 2016b). But such flooding occurs just once every few years, so in the intervening years these terns nest on the largest ox-bow lakes of rivers (Golawski et al. 2015). Being an expansive species, CHL does not occupy the same niche (habitat) in the invaded environment as in the native one and sustains substantial brood losses under appropriate weather conditions. CHN should be able to cope with inclement weather conditions far better, as it turns up very early, anticipating, as it were, the advent of the strongest winds in the breeding season; ox-bow lakes are still CHN's basic breeding habitat in east-central Poland (Golawski et al. 2015). This shows that a species nesting there for many years has higher hatching success (treated as gauge productivity, Mazzocchi et al. 1997) in comparison with species in expansion at the edge of breeding range. CHL relatively slowly inhabits new breeding areas situated west of current range ending in eastern Poland (Ławicki et al. 2011). Its nesting in Western Europe was noted concurrently with abundant appearance in Poland. However, breeding populations observed in Germany, Denmark and the Netherlands were characterised by small numbers and not every-year occurrence (Grell and Rasmussen 1997; Boele and Ebels 2007; Gruneberg and Boschert 2009, Krol 2015). Due to low breeding success noted in eastern Poland, it should be assumed that expansion of CHL is supplied by individuals nesting in areas east of Poland. Ledwon et al. (2014) arrived at similar conclusion for Whiskered Tern and explained its population increase by immigration rather than by intrinsic dynamics. 
Acknowledgements We would like to thank Ewa Droś, Paweł Żmińczuk and Kamil Kryński who carried out the surveys, and we are grateful to Peter Senn for improving the English. We are also grateful to the two anonymous reviewers for their critical remarks regarding the first version of this paper. This study complies with current Polish laws and was financially supported by the Siedlce University of Natural Sciences and Humanities with Grant number 75/94/s.

\section{Compliance with ethical standards}

Conflict of interest The authors declare no conflict of interest.

Open Access This article is distributed under the terms of the Creative Commons Attribution 4.0 International License (http:// creativecommons.org/licenses/by/4.0/), which permits unrestricted use, distribution, and reproduction in any medium, provided you give appropriate credit to the original author(s) and the source, provide a link to the Creative Commons license, and indicate if changes were made.

\section{References}

Arnold JM, Hatch JJ, Nisbet ICT (2004) Seasonal declines in reproductive success of the common tern Sterna hirundo: timing or parental quality? J Avian Biol 35:33-45

Boele A, Ebels E (2007) Succesvolle broedgevallen van Witvleugelstern in Krimpenerwaard en Sliedrechtse Biesbosch. Dutch Bird 29:342-343

Bonter DN, MacLean SA, Shah SS, Moglia MC (2014) Storminduced shifts in optimal nesting sites: a potential effect of climate change. J Ornithol 155:631-638

Boyd H (1987) Do June temperatures affect the breeding success of Dark-bellied Brent Geese Branta b. bernicla?. Bird Study 34:155-159

Burger J (1982) An overview of proximate factors affecting reproductive success in colonial birds: concluding remarks and summary of panel discussion. Colon Waterbirds 5:58-65

Burger J, Nisbet ICT, Safina C, Gochfeld M (1996) Temporal patterns in reproductive success in the endangered roseate tern (Sterna dougallii) nesting on Long Island, New York, and Bird Island, Massachusetts. Auk 113:131-142

Chapman Mosher B-A (1987) Factors influencing reproductive success and nesting strategies in Black Terns. Dissertation, Simon Fraser University

Conway CJ, Martin TE (2000) Effects of ambient temperature on avian incubation behavior. Behav Ecol 11:178-188

Cramp S (1985) The Birds of the Western Palearctic, vol 4. Oxford University Press, Oxford

Dombrowski A, Golawski A, Kasprzykowski Z et al (2014) Breeding colonies of the White-winged Tern Chlidonias leucopterus, Black Tern Ch. niger and Whiskered Tern Ch. hybrida on Mazowsze Lowland in 2013. Ornis Pol 55:219-224

Duhem C, Roche P, Vidal E, Tatoni T (2008) Effects of anthropogenic food resources on yellow-legged gull colony size on Mediterranean islands. Popul Ecol 50:91100
Fielding AH, Bell JF (1997) A review of methods for the assessment of prediction errors in conservation presence/ absence models. Environ Conserv 24:38-49

Frederiksen M, Daunt F, Harris MP, Wanless S (2008) The demographic impact of extreme events: stochastic weather drives survival and population dynamics in long-lived seabird. J Anim Ecol 77:1020-1029

García JT, Arroyo BE (2001) Effect of abiotic factors on reproduction in the centre and periphery of breeding ranges: a comparative analysis in sympatric harriers. Ecography 24:393-402

Gaston KJ (2009) Geographic range limits: achieving synthesis. Proc R Soc B 276:1395-1406

Głowaciński Z (2001) Polish red data book of animals, vertebrates. PWRiL, Warszawa

Gochfeld M, Burger J (2016) Black Tern (Chlidonias niger). In: del Hoyo J, Elliott A, Sargatal J, Christie DA, de Juana E (eds) Handbook of the birds of the world alive. Lynx Edicions, Barcelona (retrieved from http://www.hbw.com/ node/54047 on 24 Feb 2016)

Gochfeld M, Burger J, Christie DA, Kirwan GM (2016) Whitewinged Tern (Chlidonias leucopterus). In: del Hoyo J, Elliott A, Sargatal J, Christie DA, de Juana E (eds) Handbook of the birds of the world alive. Lynx Edicions, Barcelona (retrieved from http://www.hbw.com/node/54046 on 24 Feb 2016)

Golawski A, Kasprzykowski Z, Mroz E, Rzepala M, Chmielewski S (2015) The differences in habitat selection in two sympatric species of eastern Poland: the White-winged Tern (Chlidonias leucopterus) and the Black Tern (Chlidonias niger). Wilson J Ornithol 127:52-58

Golawski A, Kasprzykowski Z, Ledwon M, Mroz E, Morelli F (2016a) Brood sex-ratio in expansive and non-expansive tern species in east-central Poland. Bird Study 63:31-36

Golawski A, Mroz E, Kasprzykowski Z (2016b) Breeding performance of the White-winged Tern (Chlidonias leucopterus) in two habitat types at the edge of their distribution range. Ornis Fenn 93:225-234

Grell M, Rasmussen LM (1997) First breeding of the whitewinged black tern in Denmark. Dansk Ornitologisk Forenings Tidsskrift 91:121-124

Gruneberg C, Boschert M (2009) Weißbart- und Weißflügelseeschwalben in Deutschland: bestandsentwicklung und aktuelle Brutverbreitung. DDA-Monitoring-Rundbrief 1:9-13

Hill T, Lewicki P (2007) Statistics: methods and applications. StatSoft, Tulusa

James WW, Wunderle JM (1993) The effects of hurricanes on birds, with special reference to Caribbean islands. Bird Conserv Int 3:319-349

Kapocsy G (1979) Weißflügel- und Weißartseechwalbe. A. Ziemsen Verlag, Wittenberg Lutherstadt

Kasprzykowski Z, Polak M, Chylarecki P (2014) Effects of weather conditions, time of breeding, brood size and hatching order on Eurasian Bittern nestling growth in a food-rich fishpond habitat. Ann Zool Fenn 51:477-487

Krol M (2015) Moerassterns onder de rook van Groningen. De Grauwe Gors 42:4-11

Ławicki Ł, Niedźwiecki S, Sawicki W et al (2011) Numerous nesting of the White-winged Tern Chlidonias leucopterus in Poland in 2010. Ornis Pol 52:85-96 
Lawton JH (1996) Population abundances, geographic ranges and conservation: 1994 Witherby Lecture. Bird Study 43:3-19

Ledwoń M, Betleja J, Stawarczyk T, Neubauer G (2014) The Whiskered Tern Chlidonias hybrida expansion in Poland: the role of immigration. J Ornithol 155:459-470

Massa C, Doyle M, Fortunato RC (2014) On how Cattle Egret (Bubulcus ibis) spread to the Americas: meteorological tools to assess probable colonization trajectories. Int $\mathbf{J}$ Biometeorol 58:1879-1891

Mazzocchi IM, Hickey JM, Miller RL (1997) Productivity and nesting habitat characteristics of the Black Tern in northern New York. Colon Waterbirds 20:596-603

Møller A, Fiedler W, Berthold P (2004) Birds and climate change. Vol. Advances in ecological research. Elsevier Academic Press, Amsterdam

Newton I (1998) Population limitation in birds. Academic Press, London

Nisbet ICT, Wingate DB, Szczys P (2010) Demographic consequences of a catastrophic event in the isolated population of common terns at Bermuda. Waterbirds 33:405-410

Olson CR, Vleck CM, Vleck D (2006) Periodic cooling of bird eggs reduced embryonic growth efficiency. Physiol Biochem Zool 79:927-936

Oro D, Ruxton GD (2001) The formation and growth of seabird colonies: Audouin's gull as a case study. J Anim Ecol 70:527-533

Paillisson J-M, Reeber S, Carpentier A, Marion L (2006) Plantwater regime management in a wetland: consequences for a floating vegetation-nesting bird, whiskered tern Chlidonias hybridus. Biodivers Conserv 15:3469-3480

Paradis E, Baillie SR, Sutherland WJ, Gregory R (1998) Patterns of natal and breeding dispersal in birds. J Anim Ecol 67:518-536

Pigot AL, Owens IPF, Orme CDL (2010) The environmental limits to geographic range expansion in birds. Ecol Lett 13:705-715

Polak M, Kasprzykowski Z (2013) The effect of weather conditions on the breeding biology of the Eurasian Bittern Botaurus stellaris in eastern Poland. Ethol Ecol Evol 25:243-252
Polakowski M (2011) Early arrivals of the White-winged Tern Chlidonias leucopterus and the Whiskered Tern Chlidonias hybridus in the North-Podlasian Lowland in 2009-2010. Kulon 16:117-118

Popławska J, Grabowska K (2013) The application of selected methods for detection of tornadoes in Poland (case study). 7th European Conference on Severe Storms (ECSS2013), 3-7 June 2013, Helsinki, Finland

Ramos JA, Maul AM, Ayrton V, Bullock I, Hunter J, Bowler J, Castle G, Mileto R, Pacheco C (2002) Influence of local and large-scale weather events and timing of breeding on tropical roseate tern. Mar Ecol Prog Ser 243:271-279

Root T (1988) Environmental factors associated with avian distributional boundaries. J Biogeogr 15:489-505

StatSoft (2012) Statistica (Data analysis software system), Version 10.0. StatSoft, Tulusa

Strubbe D, Matthysen E (2014) Patterns of niche conservatism among non-native birds in Europe are dependent on introduction history and selection of variables. Biol Invasions 16:759-764

Tomiałojć L, Stawarczyk T (2003) Awifauna Polski. Rozmieszczenie, liczebność i zmiany. PTPP „pro Natura”, Wrocław

van de Pol M, Ens BJ, Heg D et al (2010) Do changes in the frequency, magnitude and timing of extreme climatic events threaten the population viability of coastal birds? J Appl Ecol 47:720-730

Veech JA, Small MF, Baccus J (2011) The effect of habitat on the range expansion of a native and an introduced bird species. J Biogeogr 38:69-77

Verhulst S, Nilsson J-A (2008) The timing of birds' breeding seasons: a review of experiments that manipulated timing of breeding. Philos Trans R Soc B 363:399-410

Wallen K, Schneider JE (1999) Reproduction in context: social and environmental influences on reproduction. MIT Press, Cambridge

Wiens JJ, Ackerly DD, Allen AP et al (2010) Niche conservatism as an emerging principle in ecology and conservation biology. Ecol Lett 13:1310-1324 